\title{
Cognitive reserve and dementia A scientometric review
}

\author{
Maria Helena Pestana', Margarida Sobral ${ }^{2}$
}

\begin{abstract}
Research into cognitive reserve (CR) and dementia is advancing rapidly. This paper analyses the intellectual structure, emerging trends and relevant shifts in the development of available knowledge. Data collected from the Web-of-Science produced an expanded network of 564 articles and 12,504 citations in the 1998-2017 period. The co-citation network visualized was characterized by a scientometric review using CiteSpace. The results revealed that author Stern $Y$ had the highest number of publications and citations. The network of journals, institutions and countries showed a central-peripheral structure with Neurology, Harvard University and the USA ranked first, respectively. While cognitive reserve remains the most prominent area of research in this field, studies related to functional ability, executive control, mortality data and reserve mechanisms have grown considerably. The identification of critical articles and the development of emerging trends highlights new insights in the area of research, better communicating key findings and facilitating the exploration of data.
\end{abstract}

Key words: cognitive reserve, dementia, intellectual structure, patterns, emerging trends, CiteSpace.

\section{RESERVA COGNITIVA E DEMÊNCIA: UMA REVISÃO CIENTOMÉTRICA}

RESUMO. A pesquisa em reserva cognitiva e demência avança rapidamente. Este artigo analisa a estrutura intelectual, tendências emergentes e mudanças relevantes no desenvolvimento do conhecimento coletivo. Dados coletados do Webof-Science, construíram uma rede expandida de 564 artigos e 12.504 citações, entre 1998-2017. A rede de cocitação visualizada foi caracterizada através de uma revisão cientométrica utilizando o CiteSpace. Os resultados revelam Stern Y com o maior número de publicações e citações. A rede de revistas científicas, instituições e países apresenta uma estrutura central-periférica, respetivamente com Neurologia, Universidade de Harvard e EUA em primeiro lugar. Enquanto a reserva cognitiva continua a ser a área de pesquisa mais proeminente neste campo, estudos relacionados à capacidade funcional, controle executivo, dados de mortalidade e mecanismos de reserva têm experimentado um crescimento considerável. A identificação de artigos críticos e o desenvolvimento de novas tendências emergentes destacam novos insights sobre a área de pesquisa, comunicando melhor as principais descobertas e facilitando a exploração de dados. Palavras-chave: reserva cognitiva, demência, estrutura intelectual, padrões, tendências emergentes, CiteSpace.

$\mathrm{D}$ ue to the progressive ageing of the population and life expectancy, increasing attention has been dedicated to the study of cognitive reserve (CR) and dementia. Dementia predominantly affects older people, and the risk of dementia rises with increasing age. Alzheimer's disease (AD) is the most common form of dementia in the elderly. ${ }^{1} \mathrm{CR}$ is a hypothetical model which reflects cognitive aging and describes the capacity of the adult brain to tolerate the effects of this neurodegenerative process, ${ }^{2}$ while dementia is a syndrome in which there is deterioration in memory, thinking, orientation, comprehension, calculus, learning capacity, language, and judgement, thinking, behavior and the

This study was conducted at the University Institute of Lisbon (ISCTE-IUL), Lisbon and Hospital Magalhães Lemos, Porto, Portugal.

${ }^{1} \mathrm{PhD}$, University Institute of Lisbon (ISCTE-IUL), Lisbon, Portugal. Research and Education Unit on Ageing (UNIFAI, ICBAS, UP). ${ }^{2}$ PhD, Psychogeriatrics Service, Hospital Magalhães Lemos, Porto, Portugal. Research and Education Unit on Ageing (UNIFAI, ICBAS, UP). CINTESIS - Center for Health Technology and Services Research (FM, UP).

Margarida Sobral. Hospital de Magalhães Lemos - Rua do Professor Álvaro Rodrigues - 4149-003 Porto - Portugal. E-mail: margaridasobral@hmlemos. min-saude.pt

Disclosure: The authors report no conflicts of interest.

Received December 08, 2018. Accepted in final form January 23, 2019. 
ability to perform everyday activities. The $\mathrm{CR}$ hypothesis suggests that individual differences in the ability to cope with $\mathrm{AD}$ pathology ${ }^{2-5}$ are consistent with the prediction that people with greater reserve can cope with advancing $\mathrm{AD}$ pathology longer before it is expressed clinically. ${ }^{2,5-7} \mathrm{CR}$ is not fixed and continues to evolve throughout the lifespan. ${ }^{6,7} \mathrm{CR}$ is not measured directly ${ }^{8}$ and the variables that pertain to lifetime experience, such as education, occupation, and leisure activities, are the most commonly used proxies for $\mathrm{CR} .2,6,8-10$ These variables help the individual retain cognitive function in old age. ${ }^{11}$ Some studies have shown that the risk of developing $\mathrm{AD}$ is reduced in individuals with higher levels of education, ${ }^{5,12-16}$ occupational attainment ${ }^{5,17-21}$ and participation in leisure activities. ${ }^{5,22-26}$ Other studies found no association between education and incident dementia. ${ }^{15,27,28}$ Furthermore, no association was found between occupational attainment and incident $\mathrm{AD}$ in several population-based longitudinal studies. ${ }^{29}$ $\mathrm{CR}$ interventions might be a key nonpharmacological approach to preventing this disease. ${ }^{6}$ Several studies on $\mathrm{CR}$ and dementia have used different methodologies, leading to disparate results.

CR and dementia involve research in several fields and disciplines such as clinical neurology, neurosciences, geriatrics and gerontology. As research in these areas advances rapidly, it is critical to keep abreast of the respective intellectual structure, emerging trends and relevant shifts in the development of available knowledge. Studies on CR and dementia have been published in a large number of journals by authors from all over the world. However, there is a need to gather systematic data on this global scientific output. Therefore, innovative studies are required to make sense of the subsequent ballooning number of publications in the area. In recent years, bibliometrics has been widely applied in various fields to identify the output of authors, institutions and countries, as well as evaluate geographic distributions and international collaborations..$^{30}$ In this study, bibliometric analysis was used to evaluate the global scientific output on $\mathrm{CR}$ and dementia, and find an approach to quantitatively and qualitatively assess the current global research. Data were based on the science citation index expanded database from the Institute of Scientific Information Web of Science database, corresponding to 564 publications and 12,504 citations referring to cognitive reserve and dementia in the 1998-2017 period. More specifically, this study aimed to analyze publications, journals, areas of research, the intellectual structure, keywords, research hotspots and emerging trends in $\mathrm{CR}$ and dementia.

\section{METHODS}

\section{Network analysis and visualization}

Bibliometric analysis is critical for conducting periodic reviews of existing research fields, identifying contributions to knowledge and for constructing substantiated arguments about the development of a field. ${ }^{31}$ The present study focused on co-citation analyses to create network visualizations of the relationships between influential publications, highlighting disciplinary contributions in an interdisciplinary field. ${ }^{32}$ CiteSpace was used to support network visualization from bibliographical sources and to quantify the science research using three types of metrics: (1) structural (betweenness centrality, modularity and silhouette), temporal (citation burst) and semantic (define cluster labels from phrases extracted from titles, abstracts and keywords or from index terms of citing articles). These metrics are useful for describing the intellectual structure of disciplines and fields, detecting existing scientific schools and academic networks, and for identifying potential research fronts, as will be seen later in the paper.

\section{Bibliographical records}

The global scientific outputs were generated from the Web-of-Science (WoS) database and analysed using CiteSpace (http://cluster.cis.drexel.edu/ cchen/ citespace/) and VosViewer (http://www.vosviewer. com/). The dimensions used as a basis for selecting the articles on cognitive reserve and dementia were: keywords, journals and years of publication. Concerning keywords, given the focus on cognitive reserve and dementia, these two words were used. To provide more scientific and accurate information about our research, only those articles with the search terms in the title, abstract or keywords of the documents were extracted for further analysis ${ }^{33}$ from the WoS database. Regarding time horizon, the analysis spans twenty years, from 1998 to 2017. Many previous articles have adopted a similar time horizon, e.g. Ye et al. ${ }^{34}$ Finally, concerning the journals, the number of selected papers explicitly focused on cognitive reserve and dementia was taken into account. Only journals published in English were included in the sample. Using these three criteria (keywords, time horizon and journals), the total sample included 564 articles, representing $82.10 \%$ of all the documents, and 12,504 citations. Based on the assumption that the citing of an article makes it relevant to the topic, ${ }^{30}$ articles not cited by other studies and therefore disconnected, were eliminated. According to Ohba et al., ${ }^{35}$ findings on highly cited articles are useful to reveal the recognition of scientific advancement and give a 
historic perspective on scientific progress. Citation, as an association-of-ideas index, offers an approach to subject control of the literature of science. ${ }^{36}$ Some papers are not relevant for a specific research stream, they are not cited by other studies and therefore remain "disconnected". Exclusion of disconnected articles from the overall sample, gave a final sample of 528 connected articles. These articles were distributed across 256 journals on the field of research, and 27 had no citations. The other $89.45 \%$ with at least one citation are distributed into a network with reasonable quality (modularity 0.4295) and low density (0.0258), suggesting they are dominated by a small number of relevant journals. The top 10 journals in the WoS represent $37.25 \%$ of all CR and dementia journals and accounted for $23.94 \%$ of total publications. Neurology and Journal of Alzheimer Disease accounted for most of research, totaling 51 documents (7.98\%), followed by Journal of the International Neuropsychological Society, Dementia and Geriatric Cognitive Disorders, International Journal of Geriatric Psychiatry, International Psychogeriatrics, American Journal of Geriatric Psychiatry, Journal of the American Geriatric Society, and Neurobiology of Aging.

The network has 2365 keywords, where 285 had the minimum number of five occurrences, and the top ones are shown by time in Figure 1. The more recent key words are marked in red, such as diagnostic guidelines, human brain, lifelong bilingualism, life style, and prevention.

The structure of the network contains 1043 institutions and is dominated by a small number of them (very low density 0.00142). At the top, institutions with more than 20 documents include: Harvard University, with 23 documents and 1504 citations, followed by Colombia University, with 26 documents and 4003 citations, and finally UCLA, with 23 documents and 653 citations. All these Institutions are in the USA.

The sample of connected articles shows a pattern of increasing publications (Figure 3), with a relative growth rate of 0.28 per year. The number of research publications is doubling every 3.28 years, which is an indicator of relatively rapid growth in the amount of research work being done on $C R$ and dementia over the last twenty years.

\section{BIBLIOGRAPHICAL LANDSCAPE Thematic clusters}

Co-citation analysis is a useful empirical technique for describing the intellectual structure of disciplines. ${ }^{37}$ This technique uses pairs of documents which often appear together in reference lists and have something

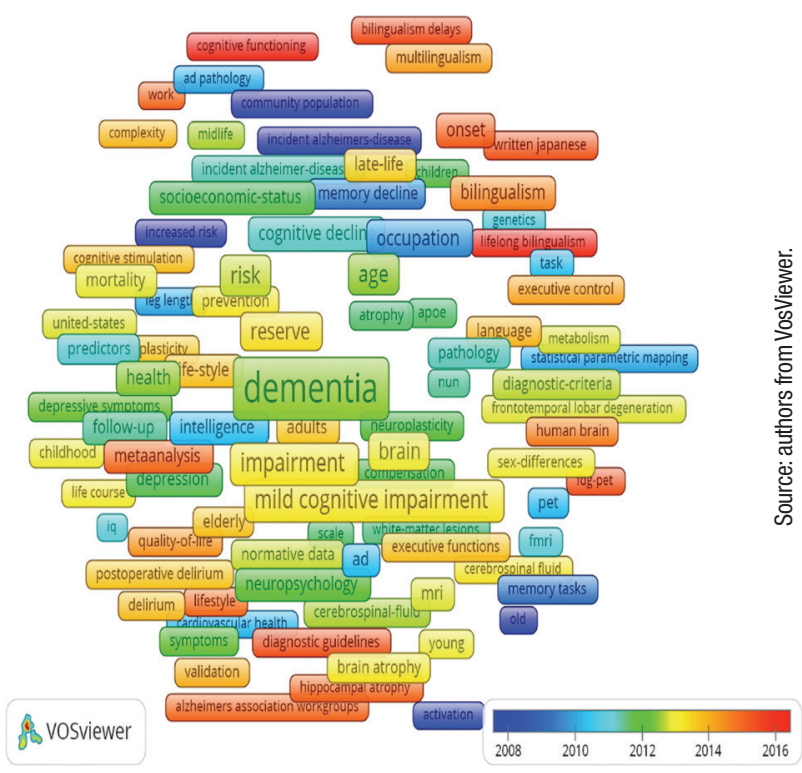

Figure 1. Network of keywords (1997-2018).

in common. ${ }^{38}$ CiteSpace divides the co-citation network into many clusters of co-cited references such that references are tightly connected within the same clusters, but loosely connected among different ones. This methodology focuses on references and, in this sense, explores the pillars of a specific research stream. Chen et $a l .^{39}$ recommended that the number of relevant clusters in the network should have more than 10 members and a silhouette value $>0.70$, which is an indicator of its homogeneity or consistency, indicating good quality of the clustering configuration.

The network generated 60 clusters (\#). The pattern of our network is dominated by small clusters (low density 0.0098 ), with clear boundaries (silhouette $>0.70$ ), such that nodes within the same group are connected tighter than nodes between different groups (high modularity 0.9549). Only seven clusters have at least 10 members and are highly homogeneous (Table 1). Each cluster is labelled by noun phrases from titles of citing articles of the cluster, ${ }^{40}$ through three different algorithms: term frequency*inverse document frequency (Tf*idf), mutual information tests (MI), and log-likelihood ratio (LLR), where this last algorithm usually yields the best result in terms of uniqueness and coverage. ${ }^{41}$

The recentness of a cluster is indicated by the average year of publication. For example, cluster \#2 has an average year of 2011 and is the most recently formed cluster, while clusters \#6 have an average year of 1993, representing the oldest clusters, as well as the least representative cluster with only twelve references.

The title of the top references that most cite the articles included in a cluster are marked in italics and 
Table 1. Major clusters of co-citation references.

\begin{tabular}{cccllll}
\hline Cluster & Size & Silhouette & Label (TF*IDF) & Label (LLR) & Label (MI) & Avg. Year \\
\hline 0 & 26 & 0.642 & Underlying cognitive reserve & Cognitive reserve & Elderly adult & 2004 \\
\hline 1 & 19 & 0.739 & Mental status I preclinical Alzheimer's disease & Functional ability & MRC CFA & 1999 \\
\hline 2 & 18 & 0.988 & Information I history & Executive control & Poststroke aphasia & 2011 \\
\hline 3 & 17 & 0.777 & Sex difference I clinical severity & Mortality data & MRC CFA & 2000 \\
\hline 4 & 16 & 0.623 & Japanese population I identification & Reserve mechanism & Ethnic variation & 2002 \\
\hline 5 & 15 & 0.602 & Reversion & National institute & Metabolic syndrome & 1998 \\
\hline 6 & 12 & 0.949 & Neuropsychological assessment & Edinburgh cohort & Cognitive reserve & 1993 \\
\hline
\end{tabular}

Source: authors (2018) from CiteSpace.

can shed some light on the research done in that cluster. The largest cluster (\#0) has 26 members, and is labelled cognitive reserve by LLR. The most active citer of $\# 0$ covering $19 \%$ of their references, is Perneczky et al., ${ }^{42}$ on "Cognitive reserve and its relevance for the prevention and diagnosis of dementia". According to these authors, progressive brain damage is undoubtedly the main cause of clinical symptoms of dementia in neurodegenerative disorders such as AD. However, the association between brain damage and cognitive symptoms is not linear. Certain interindividual differences such as a good school education or a greater brain volume are associated with a higher resilience against brain damage, usually referred to as $C R$. In subjects suffering from progressive neurodegeneration, active mechanisms, mechanisms that are associated with the ability to maintain a certain level of cognitive performance in the face of progressive neurodegeneration for a longer period, help to compensate for brain damage. The article focusses on the positive association between $\mathrm{CR}$ and the active mechanisms that contribute to the adaptation of brain activity when task difficulty level is increased. Two articles account for $15 \%$ of cluster \#0 references: Bartres-Faz and Arenaza-Urquijo, ${ }^{43}$ on "Structural and functional imaging correlates of cognitive and brain reserve hypotheses in healthy and pathological aging", focusses on brain plasticity and on a complex correspondence between active and passive components of reserve; and Whalley et al., ${ }^{44}$ on "Cognitive reserve and the neurobiology of cognitive aging", focuses on the association between $\mathrm{CR}$ and lifestyle choices (early and mild), early education, lifelong dietary habit, leisure pursuits and the retention of late life mental ability.

The second largest cluster (\#1) has 19 members and is labelled functional ability by LLR. The most active citers for this cluster are Roe et al., ${ }^{45}$ making up $26 \%$ of
\#1 references in "Alzheimer disease identification using amyloid imaging and reserve variables proof of concept", focusing on the importance of the factors that influence $\mathrm{AD}$ pathology and dementia, to improve the predictive accuracy of amyloid imaging; and Geerlings et al. ${ }^{46} \mathrm{cov}$ ering 21\% of \#1 references in "Cognitive reserve and mortality in dementia: the role of cognition, functional ability and depression", focusing on the positive association between higher $C R$ and mortality rates when clinical symptoms are more severe.

The third largest cluster (\#2) has 18 members, is the newest cluster, with an average publication year of 2011, and is labeled information by TF*IDf and executive control by LLR. The most active citers are Guzman-Velez and Tranel, ${ }^{47}$ in "Does bilingualism contribute to cognitive reserve? Cognitive and neural perspectives" and Perani and Abutalebi, ${ }^{48}$ in "Bilingualism, dementia, cognitive and neural reserve", both accounting for 33\% of \#2 references. These articles focus on the relationship between $\mathrm{CR}$ and bilingualism information.

The 4th largest cluster (\#3) has 17 members and is labeled mortality data by LLR. The most active citers are Katzman, ${ }^{49}$ in "Epidemiology of Alzheimer's disease and dementia: advances and challenges", focusing on the age dependency of dementing disorders; and Qiu et al., ${ }^{50}$ in "The influence of education on clinically diagnosed dementia incidence and mortality data from the kungsholmen project", focusing on aging of the population and on the positive association between level of education and $\mathrm{AD}$ or dementia. No effect was found between education and mortality. Both citers made up $35 \%$ of the references included in \#3.

The 5th largest cluster (\#4) has 16 members and is labelled reserve mechanism by LLR. The most active citers for this cluster are Borroni et al. ${ }^{51}$ in "Reserve mechanisms in neurodegenerative diseases: from bench to bedside 
and back again", focusing on novel therapeutic targets in neurodegenerative diseases; Daffner ${ }^{52}$ in "Promoting successful cognitive aging: a comprehensive review", exploring the positive association between $\mathrm{CR}$ and enhancing brain capacity; and Jones et al., ${ }^{53}$ in "Aging, brain disease, and reserve: implications for delirium", centered on the prevention strategies for delirium and its role in aging and neuropsychiatric disease. All these citers together comprise $25 \%$ of \#4 references.

Another major cluster corresponds to reversion, or metabolism syndrome (cluster \#5). The most active citers are Kawano et al., ${ }^{54}$ covering $20 \%$ of \# 5 references in "Effects of educational background on verbal fluency task performance in older adults with Alzheimer's disease and mild cognitive impairment", investigating the importance of subjects' educational background to analyse the effect of fluency task on the risk for developing $\mathrm{AD}$; and Bruandet et al..$^{55}$ accounting for $13 \%$ of \#5 references in "Cognitive decline and survival in Alzheimer's disease according to education level", addressing the rate of cognition declines and survival in $\mathrm{AD}$.

Finally, cluster \#6 labelled neuropsychological assessment, or Edinburgh cohort, has an average publication year of 1993. The most active citers are Basso and Bornnstein $^{56}$ in "Estimated premorbid intelligence mediates neurobehavioral change in individuals infected with HIV across 12 months", focusing on the hypothesis that estimated premorbid intelligence mediates decline in neuropsychological function in patients with stable HIV status, and Pereda et al. ${ }^{57}$ in "Factors associated with neuropsychological performance in HIV-seropositive subjects without aids", on the effect of not being on zidovudine treatment, having lower reserve capacity and being of older age, to lower the threshold for neuropsychological abnormalities in cases of early HIV infection. All these citers cover $50 \%$ of \# 6 references.

\section{The intellectual structure of CR and dementia}

CiteSpace characterizes emerging trends and patterns of change in terms of visual attributes. Each node is depicted with a series of tree-rings across the time slices. The purple ring displays the structural properties of a node. The thickness of the purple ring displays the degree of betweenness centrality, which measures the transformative potential of a scientific study, essential for the development of a knowledge domain. The size of the node indicates the strength of citations the reference received. The color of the citations rings indicates the time slices in which the citation burst occurs. Red colours indicate more recent slices while blue colours indicate the opposite.

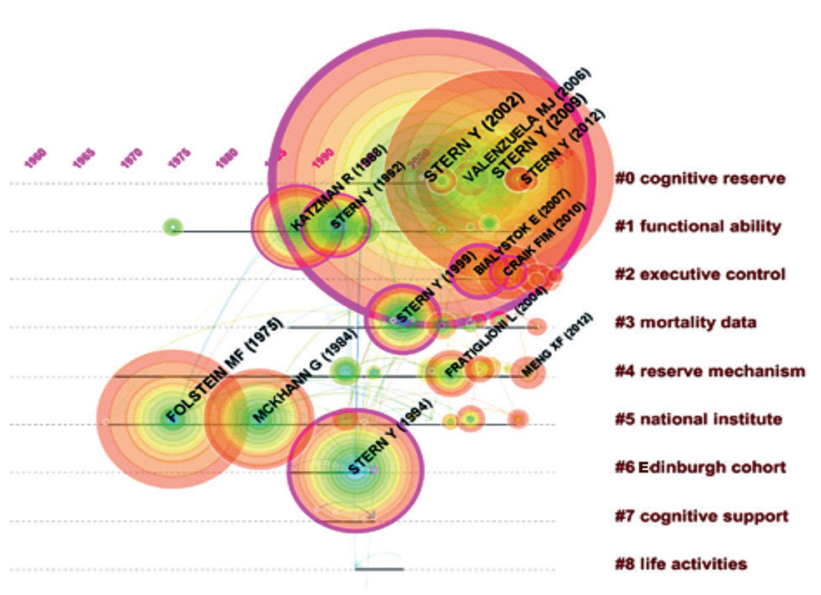

Figure 2. Timeline of co-citation clusters. Landmark articles are labeled.

Figure 2 shows a timeline visualization of the network with distinct clusters, where some landmark articles are identified by first author. Cluster \#2 has the higher number of references with a burst of citations in 2017, showing the relevance of executive control research to the current study of $C R$ and dementia. Nevertheless, Stern ${ }^{5}$ from cluster \#0 has the highest burst of citations in 2017 of all networks, showing its dominance for the current study of cognitive research.

The most cited papers have value in their revelation of advances in theory-building, and in providing a historical perspective on the progress made within a discipline. ${ }^{4}$ They are usually regarded as landmarks because of their ground-breaking contributions. The five top-cited articles are distributed between two areas of research (\#0 and \#4) between 1998-2017 (Table 2). At the top, are Stern ${ }^{5,58,59}$ and Katzman ${ }^{60}$ from cluster $\# 0$, respectively with 2570,1776, 1242, and 1036 citations; and Fratiglioni et al., ${ }^{23}$ from cluster \#4 with 1636 citations. Stern ${ }^{5,58,59}$ develops a coherent theoretical background of reserve and $C R$, and focuses on the relevance of lifelong experiences to increasing $C R$, including educational and occupational attainment, and leisure activities in later life. Katzman ${ }^{60}$ focused on the effect of education on being diagnosed with dementia at an earlier point in time. Fratiglioni et al..$^{23}$ focus on the importance of an active and socially integrated lifestyle in late life to protect against dementia and AD.

The most cited and betweenness centrality papers play an important role in different fields of $C R$ and dementia research. Betweenness centrality articles indicate their importance in bridging different stages of field development. ${ }^{61}$ Stern $Y$ is an author highly cited and belongs to three different clusters (\#0,\#1, \#3), suggesting centrality in connecting these areas of research, 
Table 2. Top-cited articles on Cognitive Reserve and Dementia.

\begin{tabular}{clcccc}
\hline Citations & Title & Author & Year & Centrality & Source \\
\hline 2570 & $\begin{array}{l}\text { What is cognitive reserve? Theory and research } \\
\text { application of the reserve concept }\end{array}$ & Stern & 2002 & 0.63 & $\begin{array}{c}\text { Journal of the International } \\
\text { Neuropsychological Society }\end{array}$ \\
\hline 1776 & Cognitive Reserve & Stern & 2009 & 0.05 & Neuropsychologia \\
\hline 1636 & $\begin{array}{l}\text { An active and socially integrated lifestyle in late life } \\
\text { might protect against dementia }\end{array}$ & Fratiglioni et al. & 2004 & 0.03 & Lancet Neurol \\
\hline 1242 & $\begin{array}{l}\text { Education and the prevalence of dementia and } \\
\text { Alzheimer's disease }\end{array}$ & Katzman & 1993 & 0.18 & Neurology \\
\hline 1036 & Cognitive reserve in ageing and Alzheimer's disease & Stern & 2012 & 0.03 & 0 \\
\hline
\end{tabular}

Source: authors (2018) from CiteSpace.

contributing to the transformative improvement in $\mathrm{CR}$ and dementia research. Stern ${ }^{58}$ has the highest level of betweenness centrality (0.63). Another central article is Bialystok et al. ${ }^{62}$ from cluster \#2, connecting \#2 (executive control) with \#0 (cognitive reserve), currently highly cited, with a citation burst from 2013 to 2017 (Table 3). This article addressed the effect of lifelong bilingualism on dementia, which maintains cognitive functioning and delays the onset of symptoms of dementia in old age by about 4 years. Stern ${ }^{58}$ and Bialystok et al., ${ }^{62}$ are also articles that have contributed to a structural change in the network, in 2002 and 2007, respectively (Figure 3).

\section{Most active clusters and references}

A citation burst can be used to detect the most active articles and areas of research. A citation burst provides evidence that a publication is associated with a surge in citations, attracting an extraordinary degree of attention from the scientific community. ${ }^{61}$ All clusters from \#0 to \#4 have bursts of citations, meaning they are representative of the diversity of interests in the field of research. Citation bursts provide a useful means of tracking the development of research areas. Cognitive reserve (\#0) has the articles with strongest citation bursts, meaning that mainly after 2002, the beginning of the burst, the major efforts of the research field concentrated in this area of research. Other research interests, mainly after 1999, involve functional ability (\#1) and mortality data (\#3) then, after 2003, on reserve mechanisms (\#4); and after 2013 in executive control (\#2). Table 3 shows the most active areas of research and articles, displayed by burst strength per cluster.

\section{Emerging trends in the network of CR and dementia}

The intellectual structure of the knowledge of co-cited references can be measured by modularity. ${ }^{13}$ Newly published articles may have little or no impact on the structure of the network, or may create a profound structural change, when deep changes occur in the modularity. Figure 3 shows the change in modularity during the 1998-2017 period. It is notable that modularity dipped mainly in 1999, 2002, 2007, and 2011. Therefore, we investigated potential emerging trends looking at publications with bursts of citations in these years, because we expected them to play an important role in changing the overall intellectual structure of $C R$

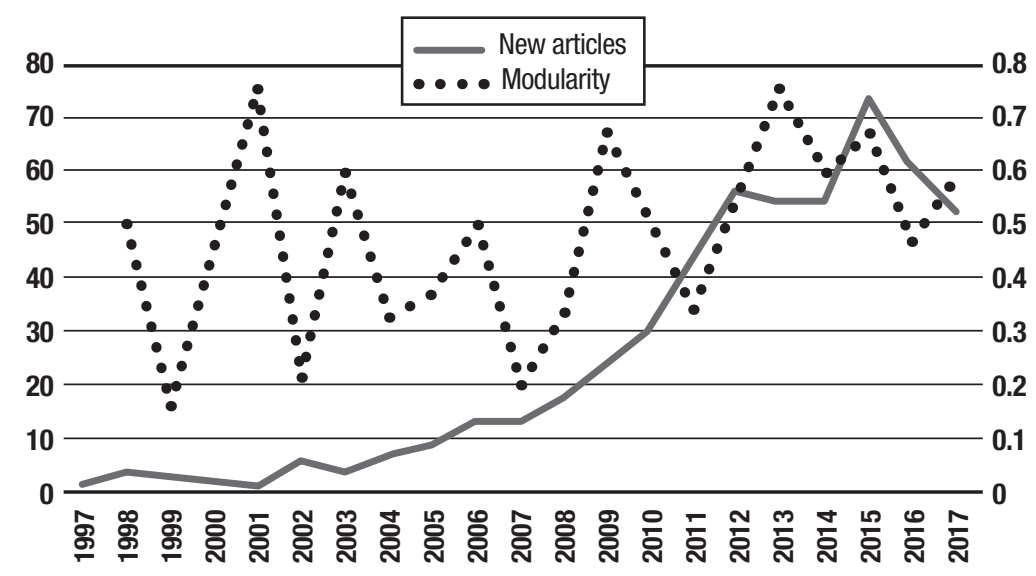

Figure 3. Structural changes in the network measured (1998-2017) 
and dementia. The top publications are marked with shading in Table 3 , and include:

In 1999, Stern ${ }^{63}$ focuses on the effect of level of education and occupational attainment on memory in $A D$ patients.

In 2002, Wilson et al..$^{64}$ focuses on the effect of frequency of participation in cognitively stimulating activities on the risk of $\mathrm{AD}$.

In 2007, the three relevant articles are: Fratiglioni \& Wang ${ }^{65}$ focuses on the effects of education, adult-life occupational work complexity, mentally and social inte- grated lifestyle in late life, as factors to affect the onset of clinical dementia and AD; Bialystok et al. ${ }^{62}$ focuses on the effect of lifelong bilingualism on dementia in old age; and Valenzuela \& Sachdev ${ }^{66}$ centers on LEQ as a tool for estimating brain reserve in older individuals.

In 2011, the three relevant articles are: Tucker \& Stern ${ }^{6}$ focuses on the effect of executive functions task on $\mathrm{CR}$; on the association between $\mathrm{CR}$ and neural efficiency, capacity, and ability; and on the fact that $C R$ is not fixed but continues to evolve during the lifespan; Gollan et al. ${ }^{67}$ focuses on the effects of bilingualism on

Table 3. Structurally and temporally significant references.

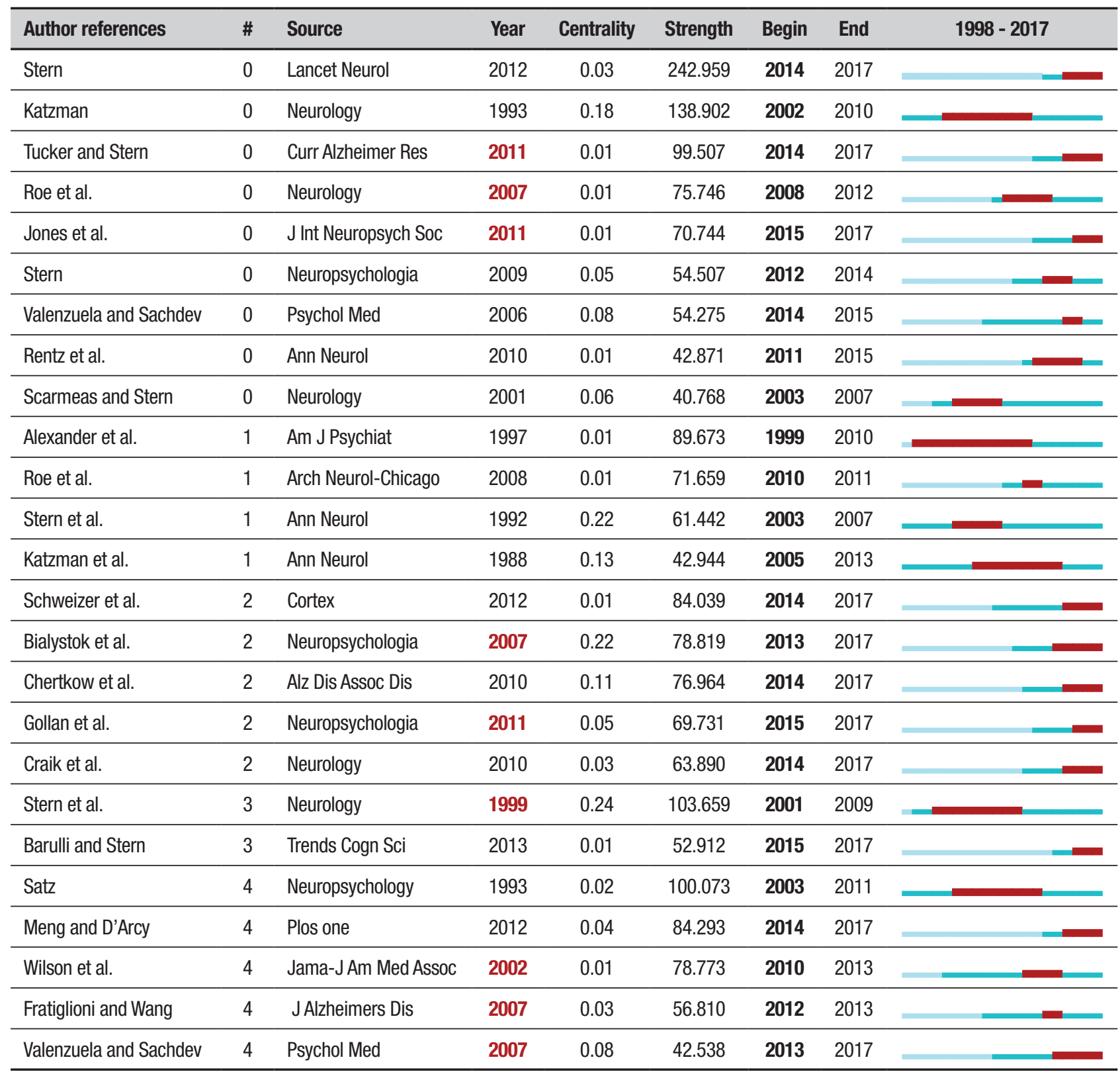

Source: authors (2018) from CiteSpace. 
CR and suggested an upper limit on the extent to which reserve can delay dementia; and Jones et al..$^{68}$ focuses on approaches for quantifying reserve using latent variable models, with an emphasis on their application in the analysis of data from observational studies.

\section{CONCLUSION}

This bibliometric study carried out during the 19982017 period has allowed a number of conclusions to be drawn in line with the objective established in the introductory section of this paper. The exploration of the literature on $\mathrm{CR}$ and dementia from WoS databases has outlined the evolutionary trajectory of the collective knowledge over the past twenty years and highlighted the areas of active pursuit and future research. Based on the network visualization and document co-citation analysis using CiteSpace and VosViewer, this study evaluated emerging trends and patterns of publications, citations, journals, institutions, and areas of research in the literature. The top clusters covered a range of interests, reflecting the interdisciplinary nature of $C R$ and dementia. They are foundational to the field of research.

To the best of our knowledge, this study represents the first attempt to apply CiteSpace to explore and visualize $C R$ and dementia knowledge. It is one of only a few investigations that have focused on co-citations as a marker of development of this domain from different perspectives. The findings of the present investigation demonstrate the potential of bibliometric visualization techniques for studying the scientific literature.

First, by visualizing the relational analysis of top authors and articles, the study provides insights into patterns of international research focus. The clustering technique used in this work identifies key articles that share similar topics. Articles that serve as an important bridge between two clusters are also detected in the network, namely Stern ${ }^{5,58,59}$ and Bialystok et al. ${ }^{62}$ Secondly, the bibliometric visualization used in this paper provides important temporal data by displaying nodes in different colours. A longitudinal view of cluster analysis and citation bursts of key articles adds a new dimension to the analysis and provides insights into the flow of major trends and collaborations. These temporal data allow researchers to identify research frontiers by highlighting emergent hot topics, authors, and articles. ${ }^{41}$

Thirdly, co-citation analysis is a useful method of providing insights into a field based on a large sample of documents. ${ }^{41}$ Multiple metrics help elucidate and explore relationships between articles and citations. Betweenness centrality can reflect the potential pivotal point and new ideas in the $\mathrm{CR}$ and dementia field; while density, modularity, and burst strength provide a more objective metric analysis of the network.

Another contribution made by the research is the understanding it promotes regarding the way knowledge is structured in the field of CR and dementia. The study of clusters, previously described, showed that cluster \#1, cluster \#3, and cluster \#4, due to bursts of citations, are the major current areas of research. Consequently, the maturity of research on this domain is evident by the fact that it has shifted from being focused mainly on CR to more specific aspects with a broader disciplinary base (functional ability, \#1; mortality data, \#3; reserve mechanisms and executive control, \#4). Therefore, this field of study is becoming more multidisciplinary, increasingly being analyzed from the different angles provided by diverse scientific approaches, which complement and enrich its content. In terms of authors' affiliations, among the top universities, the leader is located in the USA: Harvard University followed by Colombia University and UCLA. The network of journals shows a central-peripheral structure, where Neurology and Journal of Alzheimer Disease are ranked first, followed by Journal of International Neuropsychological Society. The investigation of the most cited articles has allowed the mapping of the intellectual structure of this field. Hence, the potential for development of the field of $C R$ and dementia as a research focus is immense.

The study has some limitations. First, this work was restricted to English language journals. It is likely that some of the literature may have been published in other languages. Secondly, despite the relevance of the WoS databases to $C R$ and dementia research, other important studies could have been included within other databases. Nevertheless, it is evident that bibliometric analysis has helped to characterize, both qualitatively and quantitatively, the $C R$ and dementia research field in terms of its development, trends of investigation and collaboration networks. As a result, researchers have been equipped with new tools of exploration.

The results help further understanding on the intellectual structure of this field through an innovative methodology, using co-citation analyses to understand the development of $\mathrm{CR}$ and dementia from different perspectives. The study findings demonstrate the potential of bibliometric visualization techniques to investigate the scientific literature.

Authors contributions. All authors contributed significantly to, and approved, the content of this manuscript. 


\section{REFERENCES}

1. Berr C, Wancata J, Ritchie K. Prevalence of dementia in elderly in Europe. Eur Neuropsychopharmacol. 2005;15:463-71.

2. Stern Y. Cognitive Reserve: Implications for Assessment and Interventions. Folia Phoniatr Logop. 2013;65:49-54

3. Siedlecki KL, Stern Y, Reuben A, Sacco RL, Elkind MSV, Wright CB. Construct validity of cognitive reserve in multiethnic cohort:the Northern Manhattan Study. J Int Neuropsychol Soc. 2009:15:558-69.

4. Stern Y. Elaborating a hypothetical concept:comments on the Special Series on Cognitive Reserve. J Int Neuropsychol Soc. 2011;17(4):639-42.

5. Stern Y. Cognitive reserve in ageing and Alzheimer's disease. Lancet Neurol. 2012;11:1006-12.

6. Tucker AM, Stern Y. Cognitive reserve in aging. Curr Alzheimer Res. 2011;8(4):354-60

7. Tucker AM, Stern Y. Cognitive reserve and the aging brain. In: AK Nair \& MN Sabbagh (Eds.), Geriatric Neurology. Chichester: Wiley; 2014, pp. 118-125.

8. Sobral M, Pestana MH, Paúl C. Measures of cognitive reserve in Alzheimer's disease. Trends Psychiatry Psychother. 2014;36(3):160-8.

9. Barulli D, Stern Y. Efficiency, capacity, compensation, maintenance, plasticity: emerging concepts in cognitive reserve. Trends Cogn Sci. 2013;17(10):502-9.

10. Robertson $\mathbb{H}$. A right hemisphere role in cognitive reserve. Neurobiol Aging. 2014;35(6):1375-85.

11. Staff RR, Murray AD, Deary IJ, Whalley LJ. What provides cerebral reserve? Brain. 2004:127:1191-9.

12. Evans DA, Hebert LE, Beckett LA, Scherr PA, Albert MS, Chown MJ, et al. Education and other measures of socioeconomic status and risk of incident Alzheimer disease in a defined population of older persons. Arch Neurol.1997;54:1399-405.

13. Launer LJ, Andersen K, Dewey ME, Letenneur L, Ott A, Amaducci, LA, et al. Rates and risk factors for dementia and Alzheimer's disease:results from EURODEM pooled analyses. Neurology. 1999;52:78-84.

14. Ravaglia G, Forti P, Maioli F, Martelli M, Servadei L, Brunetti N, et al. Incidence and etiology of dementia in a large elderly Italian population. Neurology. 2005;64:1525-30.

15. van Oijen M, de Jong FJ, Hofman A, Koudstaal PJ, Breteler MM. Subjective memory complaints, education, and risk of Alzheimer's disease. Alzheimers Dement. 2007;3(2):92-97.

16. Rapp SR, Espeland MA, Manson JE, Resnick SM, Bryan NR, Smoller $S$, et al. Educational attainment, MRI changes, and cognitive function in older postmenopausal women from the Women's Health Initiative Memory Study. Int J Psychiatr Med. 2013;46:121-43

17. Stern Y, Gurland B, Tatemichi TK, Tang MX, Wilder D, Mayeux R. Influence of education and occupation on the incidence of Alzheimer's disease. J Am Med Assoc. 1994;271:1004-10.

18. Schooler C, Mulatu MS, Oates G. The continuing effects of substantively complex work on the intellectual functioning of older workers. Psychol Aging. 1999;14:483-506

19. Karp A. Psychosocial factors in relation to development of dementia in late-life:a life course approach within the Kungsholmen Project;S tockholm:Karolinska Institutet. 2015

20. Daylee R. Greene. Relationship between occupational complexity and dementia risk in late life: a population study. AllnGraduate Theses and Dissertations. A dissertation submitted in partial fulfillment of the requirements for the degree of Doctor of Philosophy; Utah State University 2013.

21. Moskowitz J, Miller S. Occupational complexity as a predictor of cognitive reserve. Journal for Undergraduate Research Opportunities. Natural Sciences. 2014:38-43

22. Scarmeas N, Stern, Y. Cognitive reserve:implications for diagnosis and prevention of Alzheimer's disease. Curr Neurol Neurosci Rep. 2004;4:374-80.

23. Fratiglioni L, Paillard-Borg S, Winblad B. An active and socially integrated lifestyle in late life might protect against dementia. Lancet Neurol. 2004;3:343-53.

24. Hughes TF, Chang CC, Vander Bilt J, Ganguli M. Engagement in reading and hobbies and risk of incident dementia:the MoVIES project. Am J Alzheimers Dis Other Dement. 2010;25(5):432-8.

25. Sobral M, Paúl C. Relationship of leisure activities and Alzheimer's disease. Int J Adv Psychol. 2013;2(4):179-85.
26. Grande G, Vanacore N, Maggiore L, Cucumo V, Ghiretti R, Galimberti $D$, et al. Physical activity reduces the risk of dementia in mild cognitive impairment subjects:a cohort study. J Alzheimers Dis. 2014;39(4):833-9.

27. Graves AB, Larson EB, Edland SD, Bowen JD, McCormick WC, McCurry SM, Rice MM, Wenzlow A, Uomoto JM, et al. Prevalence of dementia and its subtypes in the Japanese American population of King County, Washington state:The Kame Project. Am J Epidemiol.1996;144:760-71.

28. Chandra V, Ganguli M, Pandav R, Johnston J, Belle S, DeKosky ST. Prevalence of Alzheimer's disease and other dementia in rural India:the Indo-US study. Neurology. 1998;51(4):1000-8.

29. Helmer C, Letenneur L, Rouch I, Richard-Harston S, Barberger-Gateau P. Fabrigoule $\mathrm{C}$, et al. Occupation during life and risk of dementia in French elderly community residents. J Neurol Neurosurg Psychiatry. 2001;71(3):303-9.

30. Chen $\mathrm{C}, \mathrm{Hu} Z$ Z, Liu S, Tseng $\mathrm{H}$. Emerging trends in regenerative medicine: a scientometric analysis in CiteSpace. Expert Opin Biol Ther. 2012; 12(5):593-608

31. Denyer D, Tranfield D. Using qualitative research synthesis to build an actionable knowledge base. Manag Decision. 2006;44(2):213-27.

32. White H D, Griffith BC. Author co-citation: A literature measure of intellectual structure. J Am Soc Inf Sci. 1981;32(3):163-71.

33. Fu HZ, Wang MH, Ho YS. The most frequently cited adsorption research articles in the Science Citation Index (Expanded). J Colloid Interface Sci. 2012;379(1):148-56

34. Ye Q, Li T, Law R. A co-authorship network analysis of tourism and hospitality research collaboration. Journal of Hospitality \& Tourism Research. 2013;37(1):51-76.

35. Ohba N, Nakao K, Isashiki Y, Onba A. The 100 most frequently cited articles in ophthalmology journals. Arch Ophthalmol. 2007;125(7):952-60.

36. Garfield E.Citation indexes to science:A new dimension in documentation through the association of ideas. Science.1955;122(3159):108-11.

37. Benckendorff P, Zehrer A. A network analysis of tourism research. Ann Tourism Res. 2013;43:121-49.

38. Xiao H, Smith S.L. Knowledge impact an appraisal of tourism scholarship. Ann Tourism Res. 2008;35(1):62-83

39. Chen C, Dubin R, Kim MC. Emerging trends and new developments in regenerative medicine:A scientometric update (2000-2014). Exp Opin Biol Ther. 2014:14(9):1295-317.

40. Chen C, Ibekwe-SanJuan F, Hou J. The structure and dynamics of cocitation clusters:A multiple-perspective cocitation analysis. J Am Soc In Sci Technol. 2010;61 (7):1386-409.

41. Chen C. Citespace II:Detecting and visualizing emerging trends and transient patterns in scientific literature. J Am Soc Inf Sci Technol. 2006;57(3):359-77

42. Perneczky R, Alexopoulos P, Schmid G, Sorg C, Förstl H, Diehl-Schmid $J$, Kurz, A. Cognitive reserve and its relevance for the prevention and diagnosis of dementia. Nervenarzt. 2011;82(3):325-30:332-35.

43. Bartres-Faz D. Structural and functional imaging correlates of cognitive and brain reserve hypotheses in healthy and pathological aging. Brain Topog. 2011;24(3-4):340-57.

44. Whalley LJ. Cognitive reserve and the neurobiology of cognitive aging Aging Res Rev. 2004;3(4):369-82.

45. Roe CM. Alzheimer disease identification using amyloid imaging and reserve variables proof of concept. Neurology. 2010;75(1):42-8.

46. Geerlings MI, Deeg DJ, Penninx BW, Schmand B, Jonker C, Bouter LM, et al. Cognitive reserve and mortality in dementia: the role of cognition, functional ability and depression. Psychol Med. 1999;29(5):1219-26.

47. Guzman-Velez E, Tranel D. Does bilingualism contribute to cognitive reserve? Cognitive and neural perspectives. Neuropsychology. 2015;29(1):139-50.

48. Perani D, Abutalebi J. Bilingualism, dementia, cognitive and neural reserve. Curr Opin Neurol. 2015;28(6):618-25.

49. Katzman R. Epidemiology of Alzheimer's Disease and Dementia: Advances and Challenges. In: Alzheimer's Disease. K Iqbal, SS Sisodia and B Winblad (editors); New York, USA: John Wiley \& Sons, Ltda; 2002, pp.3-10

50. Quu C, Bäckman L, Winblad B, Agüero-Torres H, Fratiglioni L. The influence of education on clinically diagnosed dementia incidence and mortality data from the Kungsholmen Project. Arch Neurol. 2001;58(12): 2034-9. 
51. Borroni B, Premi E, Bozzali M, Padovani A. Reserve mechanisms in neurodegenerative diseases:from bench to bedside and back again. Curr Med Chem. 2012;19(36):6112-8.

52. Daffner KR. Promoting successful cognitive aging:a comprehensive review. J Alzheimers Dis. 2010;19(4):1101-22.

53. Jones RN, Fong TG, Metzger E, Tulebaev S, Yang FM, Alsop DC, et al Aging, Brain Disease, and Reserve:Implications for Delirium. Am J Geriatr Psychiatry. 2010;18(2):117-27.

54. Kawano N, Umegaki H, Suzuki Y, Yamamoto S, Mogi N, Iguchi A Effects of educational background on verbal fluency task performance in older adults with Alzheimer's disease and mild cognitive impairment. Int Psychogeriatr. 2010;22(6):995-1002.

55. Bruandet A, Richard F, Bombois S, Maurage CA, Masse I, Amouye P. Pasquier F. Cognitive Decline and Survival in Alzheimer's Disease according to Education Level. Dement Geriatr Cogn Dis. 2008;25:74-80

56. Basso MR, Bornstein RA. Estimated premorbid intelligence mediates neurobehavioral change in individuals infected with HIV across 12 months. J Clin Exp Neuropsychol. 2000;22(2):208-18.

57. Pereda M, Ayuso-Mateos JL, Gomez del Barrio A, Echevarria S, Farinas M, García Palomo D, et al. Factors associated with neuropsychological performance in HIV seropositive subjects without AIDS. Psychol Med. 2002;30(1):205-17.

58. Stern Y. What is cognitive reserve? Theory and research application of the reserve concept. J Int Neuropsychol Soc. 2002;8(3):448-60.

59. Stern Y. Cognitive Reserve. Neuropsychologia. 2009;47(10):2015-28.
60. Katzman R. Education and the prevalence of dementia and Alzheimer's disease. Neurology. 1993;43(1):13-20.

61. Chen C. Searching for intellectual turning points: Progressive knowledge domain visualization. Proc Natl Acad Sci U S A. 2004;101(1):5303-10.

62. Bialystok E, Craik, Freedman M. Bilingualism as a protection against the onset of symptoms of dementia. Neuropsychologia. 2007;28;45(2):459-64.

63. Stern $Y$, Albert S, Tang M-X, Tsai WY. Rate of memory decline in AD is related to education and occupation. Cognitive reserve? Neurology. 1999;53(9):1942.

64. Wilson RS, Mendes De Leon CF, Barnes LL, Schneider JA, Bienias JL, Evans DA, Bennett DA. Participation in cognitively stimulating activities and risk of incident Alzheimer disease. JAMA. 2002;287(6):742-8.

65. Fratiglioni $L$, Wang $H X$. Brain reserve hypothesis in dementia. J Alzheimers Dis. 2007;12(1):11-22.

66. Valenzuela M, Sachdev P. Assessment of complex mental activity across the lifespan: development of the Lifetime of Experiences Questionnaire (LEQ). Psychol Med. 2007;37(7):1015-25.

67. Gollan TH, Salmon DP, Montoya RI, Galasko DR. Degree of Bilingualism Predicts Age of Diagnosis of Alzheimer's Disease in LowEducation but not in Highly-Educated Hispanics. Neuropsychologia. 2011;49(14):3826-30.

68. Jones RN, Manly J, Glymour MM, Rentz DM, Jefferson AL, Stern Y. Conceptual and measurement challenges in research on cognitive reserve. J Int Neuropsychol Soc. 2011;17(4):593-601. 